\title{
Analgesic, anti-inflammatory and antipyretic studies on the residual aqueous fraction of Uapaca togoensis (Pax) stem bark in rodents
}

\author{
Amina B. OLORUKOOBA ${ }^{1 *}$, Ferhat KHAN ${ }^{1}$, Yahya M. SANI ${ }^{2}$, Asmau N. HAMZA ${ }^{2}$ and \\ Aisha O. MUSA ${ }^{3}$ \\ ${ }^{1}$ Department of Pharmacology and Therapeutics; ${ }^{2}$ Department of Pharmaceutical and Medicinal Chemistry; \\ Faculty of Pharmaceutical Sciences, Ahmadu Bello University, Zaria. Nigeria. \\ ${ }^{3}$ Department of Botany, Faculty of Life Sciences, Ahmadu Bello University, Zaria. Nigeria.
}

Received 21 $1^{\text {st }}$ July 2020; Accepted $24^{\text {th }}$ August 2020

\begin{abstract}
Uapaca togoensis Pax. (Euphorbiaceae) is used in traditional medicine to treat several diseases including pain, inflammation and fever. This study investigated analgesic, anti-inflammatory and anti-pyretic effects of the residual aqueous fraction of the plant. Preliminary phytochemical screening and acute toxicity studies were conducted. Analgesic activity was evaluated using acetic acid-induced writhing, hot plate and formalin-induced pain tests at doses of 250,500 and $1000 \mathrm{mg} / \mathrm{kg}$, p.o. Anti-inflammatory and antipyretic activities were investigated using carrageenaninduced paw edema and Brewer's yeast-induced pyrexia model respectively in rats. Oral median lethal dose of the fraction was found to be greater than $5000 \mathrm{mg} / \mathrm{kg}$. The fraction significantly $(\mathrm{p}<0.05)$ reduced the number of acetic acid-induced writhes and increased the reaction time of mice to thermal stimuli. In the formalin test, a significant $(\mathrm{p}<0.05)$ reduction in mean pain score was observed at the second phase. A significant $(\mathrm{p}<0.05)$ decrease in paw edema at the $4^{\text {th }}$ and $5^{\text {th }}$ hours and a reduction in temperature was also observed at the $22^{\text {nd }}$ hour. Phytochemical screening revealed the presence of saponins, tannins, steroids, cardiac glycosides, flavonoids, alkaloids and triterpenes. The result of the study revealed that the fraction possesses analgesic, anti-inflammatory and antipyretic activities, validating the folkloric use of the plant.
\end{abstract}

Keywords: Analgesic, Anti-inflammatory, Anti-pyretic, Uapaca togoensis, Residual Aqueous Fraction

\section{INTRODUCTION}

Pain, inflammation and fever (pyrexia) are common symptoms or manifestations of numerous diseases affecting millions of people globally [1]. Pain, defined as an unpleasant sensory and emotional experience associated with actual or potential tissue damage or described in terms of such damage [2], is one of the most frequent reasons for which patients seek to consult with physicians [3]. Pain does not only adversely affect the quality of life of individuals, it also has a negative impact socially and economically [4]. Inflammation on the other hand is a complex biological protective response of vascular tissues to harmful stimuli which may be triggered by mechanical injuries, microbial infections, burns, allergens and other noxious stimuli [5].

*Correspondence. E-mail: aolorukooba@gmail.com Tel: +234-8057665703.

ISSN 0189-8442

(cc) EY-NC 2020. Published by Faculty of Pharmaceutical Sciences, University of Jos, Nigeria. Under Creative Commons Attribution-NonCommercial 4.0 International License. https://creativecommons.org/licenses/by-nc/4.0/ 
While pyrexia is a unique defensive host mechanism which occurs in response to pyrogenic infection, tissue damage, graft rejection, malignancy, or other diseases resulting in an increase in body temperature [6].

Pain, fever and inflammation are associated with the production of prostaglandins [7]. Nonsteroidal antiinflammatory drugs (NSAIDs), opioids and steroids are drugs currently used in the management of pain, inflammation and fever [8]. However, these drugs have been reported to cause numerous side effects such as gastrointestinal disturbances, renal damage, sedation, constipation, respiratory depression and possible dependence in patients [9, 10]. This situation has led to an increasing interest to discover more effective therapeutic drugs with possibly fewer side effects from natural sources, medicinal plants inclusive. According to the World Health Organization nearly $80 \%$ of the world population rely on plant-based drugs for their health care needs [11]. Thus, investigating the efficacy of medicinal plants used in the management of pain, inflammation and fever may open up opportunities to discover newer non-toxic, more potent, efficacious, and safe drugs.

Uapaca togoensis belonging to the family Euphorbiaceae has been used traditionally for the treatment of pneumonia, cough, fatigue, fever, rheumatic pain, vomiting and epilepsy [12]. The plant is widely distributed in West and Central Africa and found mostly in fringing forests and savannah woodlands [13]. It is an evergreen tree that grows between $13-20 \mathrm{~m}$ tall with reddish brown wood and leaves about $25 \mathrm{~cm}$ long and $15 \mathrm{~cm}$ wide. Various parts of the plant have been previously investigated and shown to possess antibacterial [12], larvicidal activity [14], antifugal and antimicrobial [15, 16], antiplasmodial [17] and cytotoxic [18] activities. Although the analgesic and antiinflammatory activities of the crude methanol extract of the plant have been reported [19], there is no study on the residual aqueous fraction of the plant. The aim of this study was therefore to evaluate the in-vivo analgesic, anti-inflammatory and anti-pyretic activities of the fraction.

\section{EXPERIMENTAL}

Drug and chemicals. Acetyl salicylic acid, Methanol, Carrageenan (Sigma-Aldrich, St. Louis U.S.A), Ethyl acetate and N-butanol (BDH Ltd Poole, England), Glacial acetic acid (Searle Essex, England), Morphine sulphate BP (Martindale Pharmaceuticals, Ramford, Essex)

Equipment. Orogastric canula, Syringes, Stop Clock, Hot Plate (Ugo Basile, Socrel model DS37, Italy), Balance (Cham II, Gallenkamp, U. K.), Vernier caliper

Collection and identification of plant material. The leaves, fruits and stems of Uapaca togoensis were collected in Edumoga district of Okpopokwu Local Government Area, Benue State, Nigeria. The plant sample was identified and authenticated at the Herbarium Unit, Department of Botany, Ahmadu Bello University, Zaria. The sample was compared with a deposited specimen in the Herbarium and Voucher number (1279) was issued to serve as reference.

Plant extraction and fractionation. The stem bark was air-dried under shade for two weeks to ensure complete dryness. It was subsequently size reduced with a mortar and pestle. The fine powdered sample $(2 \mathrm{~kg})$ was cold-macerated with $15 \mathrm{~L}$ of $70 \% \mathrm{v} / \mathrm{v}$ methanol in water with occasional shakings; filtered and the filtrate was concentrated to dryness by allowing to evaporate at room temperature. The resultant dried extract (methanol extract) had characteristic pleasant smell and was dark red in appearance. Fractionation of the methanol stem bark extract of Uapaca togoensis was conducted according to the method of Ciulei [20]. Briefly, the methanol 
extract was dissolved in distilled water and transferred into a separating funnel. The aqueous portion was partitioned with ethyl acetate to obtain the ethyl acetate fraction. Then the aqueous portion was partitioned again with n-butanol to obtain the n-butanol fraction. Finally, the left-over aqueous portion was referred to as residual aqueous fraction, (RAUT) the fraction of interest.

Animals. Swiss albino mice (18-22 g) and Wistar rats (180-200 g) were obtained from Animal House Facility, Department of Pharmacology and Therapeutics, Ahmadu Bello University, Zaria, Nigeria. They were maintained under good laboratory care, fed with standard animal feed and allowed free access to water ad libitum. The animals were used in compliance with the National Institute of Health Guide for the Care and use of Laboratory Animals and the Ahmadu Bello University Animal Use and Care Protocol.

Phytochemical screening. Phytochemical investigations of RAUT were carried out using standard methods and tests as described by [21].

Acute toxicity study in mice and rats. Acute toxicity test for RAUT was carried out based on Lorke's method [22]. In the first phase of the study, three groups containing three mice each were administered orally with the fraction at doses of 10,100 and $1000 \mathrm{mg} / \mathrm{kg}$. The animals were observed for signs of toxicity and death for the first $4 \mathrm{~h}$ and intermittently for 24 h. In the second phase, three groups of one animal each were administered the fraction orally at doses of 1600, 2900 and $5000 \mathrm{mg} / \mathrm{kg}$. The animals were also observed for signs of toxicity and death for the first $4 \mathrm{~h}$ and intermittently for $24 \mathrm{~h}$. The $\mathrm{LD}_{50}$ value was determined by calculating the geometric mean of the lowest dose that caused death and the highest dose for which the animal survived. The same experiment was repeated in rats.

\section{Analgesic studies}

Acetic acid-induced writhes test in mice. The method previously described by Koster et al., [23] was adopted to screen the fraction for peripherally acting analgesic activity. Thirty (30) mice of either sex were randomly divided into five groups of six mice each. Group I which served as the negative control received distilled water $(10 \mathrm{ml} / \mathrm{kg})$, while the mice in groups II, III and IV were given RAUT at doses of 250, 500 and $1000 \mathrm{mg} / \mathrm{kg}$. Group V the standard drug received Aspirin (150 $\mathrm{mg} / \mathrm{kg}$ ). All extract and drug administrations were through the oral route. Sixty minutes post-treatment, acetic acid $(0.6 \% \mathrm{v} / \mathrm{v}, 10$ $\mathrm{ml} / \mathrm{kg}$ ) was administered intraperitoneally to each mouse. Five minutes after the injection of acetic acid, mice were placed in individual cages and the number of abdominal writhes was counted for each mouse for a period of 10 minutes. The percentage inhibition of writhes was calculated using the formula below:

Percentage inhibition $=\{$ (Average number of writhes forcontrol - Average number of writhes for test $) \div$ Average number of writhes for control $\} \times 100$

Formalin-induced pain test in rats. The formalin-induced pain test was carried out in rats according to the method described by Tjolsen et al., [24]. Thirty (30) rats were divided into five groups of six rats each and pre-treated as follows: Groups I and V were treated with distilled water $(1 \mathrm{ml} / \mathrm{kg}$, negative control) and morphine $(5 \mathrm{mg} / \mathrm{kg}$, positive control) respectively. Groups II, III and IV received RAUT at doses of 250, 500 and 1000 $\mathrm{mg} / \mathrm{kg}$. All treatments were through the oral route. One-hour post-treatment, $20 \mu \mathrm{L}$ of formalin (freshly prepared $2.5 \%$ formalin in saline) was injected subcutaneously into the right hind paw of each rat. Rats were placed individually in an observation chamber and monitored. The responses observed were recorded for 5 minutes (neurogenic phase) and for 15- 60 minutes (inflammatory phase) after formalin injection. Behavioral responses 
observed after the formalin injection were graded as scores based on the following scale: 0 (Ability of rat to walk or stand on injected hind paw); 1 (Partial elevation of injected paw); 2 (Total elevation of injected paw); 3 (Biting or licking of the injected paw).

Hot plate test in mice. The method previously described by Eddy and Leimbach [25] was used to screen the fraction for centrally acting analgesic activity. The temperature of the hot plate was maintained at $45 \pm 0.5^{\circ} \mathrm{C}$. Only animals which responded when placed on the hot plate within a period of $30 \mathrm{~s}$ were selected for the experiment. Thirty of the selected mice were randomly divided into five groups consisting of six mice each. Groups I and V were orally treated with distilled water (10 $\mathrm{ml} / \mathrm{kg}$ negative control) and morphine (5 $\mathrm{mg} / \mathrm{kg}$ positive control) respectively. Groups II, III and IV were orally pre-treated with RAUT at doses of 250,500 and $1000 \mathrm{mg} / \mathrm{kg}$ respectively. A cut off time of $20 \mathrm{~s}$ was used to avoid paw damage. One-hour post treatment, the time taken for each animal to either jump, lick or flutter their paws was taken as the reaction time and recorded at 30,60, 90 and 120 minutes.

\section{Anti-inflammatory Study}

Carrageenan-induced rat paw edema in rats. This test was used to determine the antiinflammatory activity of RAUT by the method of Winter et al., [26]. Thirty (30) rats were randomly divided into five groups of 6 rats each. Group I received distilled water (1 $\mathrm{ml} / \mathrm{kg}$ ) and served as negative control. Groups II, III and IV were administered with RAUT $250, \quad 500$ and $1000 \mathrm{mg} / \mathrm{kg}$ of RAUT respectively. Group V the positive control received aspirin $(150 \mathrm{mg} / \mathrm{kg})$. All administrations were through the oral route. One-hour post-treatment each $0.1 \mathrm{ml}$ of carrageenan $(1 \% \mathrm{w} / \mathrm{v}$ in distilled water) was injected subcutaneously into the sub plantar region of the left hind paw of each rat. The hind paw diameter was measured and recorded at times $0,1,23,4$ and $5 \mathrm{~h}$ using a vernier caliper.
The percentage inhibition of oedema was calculated for each group using the formular below.

Percentage inhibition $=\{($ Mean increase in oedema for control - Mean increase in oedema for treated) $\div$ Mean increase in oedema for control $\} \times 100$

Antipyretic study. Antipyretic activity was evaluated in rats using the method described by Somezeet et al., [27]. The normal body temperature of each rat was checked by using digital thermometer at the beginning of the study. Pyrexia was induced in all rats by injection of $20 \%$ aqueous suspension of brewer's yeast (Saccharomyces cerevisiae) at a dose of $10 \mathrm{ml} / \mathrm{kg}$ subcutaneously below the nape of each rat. Animals were fasted with free access to only water ad libitum, after injection of yeast for $19 \mathrm{~h}$. Rectal temperature of each rat was then recorded and pyrexia was confirmed by increase in temperature of between $0.5-1{ }^{\circ} \mathrm{C}$, while animals showing less than $1{ }^{\circ} \mathrm{C}$ rise in temperature were excluded from the experiment. The selected rats were randomly divided into 5 groups of 6 rats each. Group I received distilled water $(1 \mathrm{ml} / \mathrm{kg})$, group $\mathrm{V}$ received aspirin $(150 \mathrm{mg} / \mathrm{kg})$ as a standard drug, while groups II-IV received 250,500 and $1000 \mathrm{mg} / \mathrm{kg}$, p.o. doses of RAUT. The rectal temperature of the groups was recorded at $1 \mathrm{~h}$ intervals for $4 \mathrm{~h}$.

Statistical analysis. Results obtained were expressed as Mean \pm SEM. The data were analyzed using one-way analysis of variance (ANOVA) followed by Dunnett's post hoc test (for acetic acid-induced abdominal writhes), repeated measures ANOVA followed by Bonferonni's post hoc test (for hot plate and carrageenan-induced paw oedema test) and one-way ANOVA followed by Tukey's multiple comparison post hoc test (for formalin-induced pain test). Values with $\mathrm{p} \leq$ 0.05 were considered as statistically significant. 


\section{RESULTS}

Phytochemical constituents in residual aqueous fraction of Uapaca togoensis. Phytochemical screening of the residual aqueous fraction of Uapaca togoensis revealed the presence of alkaloids, tannins, glycosides, saponins, flavonoids, steroids and triterpenes (Table 1).

Acute toxicity study in mice and rats. There were no signs of toxicity or mortality observed for all doses of the fraction administered orally to both mice and rats. The oral $\mathrm{LD}_{50}$ was thus estimated to be greater than $5000 \mathrm{mg} / \mathrm{kg}$ in both mice and rats.

Acetic acid-induced abdominal writhes in mice. The fraction significantly $(p<0.05)$ reduced the number of acetic acid-induced writhes in mice compared to the control (Table 2).

Hot plate test in mice. The fraction at 500 and $1000 \mathrm{mg} / \mathrm{kg}$ significantly $(\mathrm{p}<0.05)$ increased mean reaction time to the pain stimulus at 60 and 90 mins compared to the distilled water treated group. The significant $(\mathrm{p}<0.05)$ prolongation in mean reaction time produced by the standard drug (morphine, $5 \mathrm{mg} / \mathrm{kg}$ ) was however greater than that produced by the fraction (Table 3).

Formalin-induced pain test in mice. The residual aqueous fraction significantly $(\mathrm{p}<$ 0.05 ) reduced the mean pain score at all tested doses (250, 500 and $1000 \mathrm{mg} / \mathrm{kg}$ ) doses compared to the control only at the second phase of the study (Figure 1).

Carrageenan-induced paw oedema in rats. The fraction significantly $(p<0.05)$ decreased paw oedema at all the administered doses producing maximum inhibition of $64.9 \%$, $69.71 \%$ and $71.15 \%$ at the 250,500 and 1000 $\mathrm{mg} / \mathrm{kg}$ doses respectively in the $5^{\text {th }}$ hour (Table 4). The standard drug (aspirin, $150 \mathrm{mg} / \mathrm{kg}$ ) produced maximum inhibition $(88.94 \%)$ at the $5^{\text {th }}$ hour.

Brewer's yeast-induced pyrexia test in rats. RAUT produced a dose dependent reduction in rectal temperature at all doses which was statistically significant $(\mathrm{p}<0.05)$ at the $22 \mathrm{nd}$ hour compared to the 19th hour (Figure 2).

Table 1: Phytochemical Constituents Present in the Residual Aqueous Fraction of Uapaca togoensis

\begin{tabular}{ccc}
\hline Phytochemical Constituent & Test & RAUT \\
\hline Anthraquinones & Borntrager & Absent \\
Steroids & Liebermann-Burchard & Present \\
Triterpenes & Salkowski & Present \\
Glycosides & Keller-Kiliani & Present \\
Saponins & Frothing & Present \\
Tannins & Ferric chloride & Present \\
Flavonoids & Sodium hydroxide & Present \\
Alkaloids & Meyer & Present \\
\hline RAUT = Residual Aqueous Fraction of Uapaca togoensis
\end{tabular}

Table 2: Effect of Residual Aqueous Fraction of Uapaca togoensis on Acetic acid-induced Writhes in Mice

\begin{tabular}{lcc}
\hline Treatment $(\mathrm{mg} / \mathrm{kg})$ & Mean Number of Writhes \pm SEM & Percentage Inhibition $(\%)$ \\
\hline DW $10 \mathrm{ml} / \mathrm{kg}$ & $29.67 \pm 1.67$ & - \\
RAUT 250 & $11.00 \pm 1.10^{\mathrm{a}}$ & 62.9 \\
RAUT 500 & $12.10 \pm 0.87^{\mathrm{a}}$ & 59.2 \\
RAUT 1000 & $9.33 \pm 1.29^{\mathrm{a}}$ & 68.6 \\
ASP 150 & $6.60 \pm 0.96^{\mathrm{a}}$ & 77.7 \\
\hline
\end{tabular}

Values represented as Mean $\pm \mathrm{SEM},{ }^{\mathrm{a}}=\mathrm{p}<0.05$ versus distilled water (negative control); Data analyzed by One-way ANOVA followed by Dunnett's post hoc test; DW = Distilled Water; RAUT = Residual aqueous fraction of Uapaca togoensis; $\mathrm{n}=6$ 
Table 3: Effect of Residual Aqueous Fraction of Uapaca togoensis on Hot Plate Test in Mice

\begin{tabular}{llllll}
\hline Treatment & \multicolumn{5}{c}{ Mean Reaction Time Response (s) \pm SEM } \\
$(\mathrm{mg} / \mathrm{kg})$ & $0 \mathrm{~min}$ & $30 \mathrm{~min}$ & $60 \mathrm{~min}$ & $90 \mathrm{~min}$ & $120 \mathrm{~min}$ \\
\hline DW 1 ml/kg & $1.63 \pm 0.12$ & $1.78 \pm 0.23$ & $2.07 \pm 0.33$ & $1.40 \pm 0.10$ & $1.37 \pm 0.12$ \\
RAUT 250 & $1.67 \pm 0.21$ & $2.67 \pm 0.21$ & $3.00 \pm 0.37$ & $3.00 \pm 0.26$ & $2.33 \pm 0.21$ \\
RAUT 500 & $1.50 \pm 0.22$ & $2.17 \pm 0.17$ & $3.00 \pm 0.00^{\mathrm{a}}$ & $3.50 \pm 0.37^{\mathrm{a}}$ & $2.17 \pm 0.31$ \\
RAUT 1000 & $1.33 \pm 0.21$ & $2.33 \pm 0.33$ & $3.67 \pm 0.21^{\mathrm{a}}$ & $3.60 \pm 0.26^{\mathrm{a}}$ & $2.00 \pm 0.00$ \\
MOR 5 & $1.67 \pm 0.21$ & $5.07 \pm 0.63^{\mathrm{a}}$ & $5.05 \pm 0.37^{\mathrm{a}}$ & $6.40 \pm 0.24^{\mathrm{a}}$ & $6.37 \pm 0.53^{\mathrm{a}}$ \\
\hline
\end{tabular}

Values are presented as Mean \pm SEM. Data analyzed using repeated measures ANOVA followed by Bonferroni post hoc test; ${ }^{\mathrm{a}}=\mathrm{p}<0.05$ statistically significant increase in reaction times compared to distilled water (negative control) group; DW = Distilled Water; RAUT = Residual Aqueous Fraction of Uapaca togoensis, $\mathrm{n}=6$

Table 4: Effect of Residual Aqueous Fraction of Uapaca togoensis on Carrageenan-induced Paw 0edema in Rats

\begin{tabular}{|c|c|c|c|c|c|}
\hline \multirow{2}{*}{$\begin{array}{l}\text { Treatments } \\
(\mathrm{mg} / \mathrm{kg})\end{array}$} & \multicolumn{4}{|c|}{ Mean Increase in Rats Paw Diameter (mm) } & \multirow[b]{2}{*}{$5 \mathrm{~h}$} \\
\hline & $1 \mathrm{~h}$ & $2 \mathrm{~h}$ & $3 \mathrm{~h}$ & $4 \mathrm{~h}$ & \\
\hline DW & $1.01 \pm 0.11$ & $2.24 \pm 0.32$ & $2.30 \pm 0.21$ & $2.26 \pm 0.31$ & $2.08 \pm 0.16$ \\
\hline \multirow[t]{2}{*}{ RAUT 250} & $0.74 \pm 0.13$ & $1.20 \pm 0.15$ & $1.16 \pm 0.10$ & $0.75 \pm 0.06^{\mathrm{a}}$ & $0.73 \pm 0.07^{\mathrm{a}}$ \\
\hline & $(26.73)$ & $(46.42)$ & $(49.57)$ & $(66.81)$ & $(64.90)$ \\
\hline \multirow[t]{2}{*}{ RAUT 500} & $0.91 \pm 0.11$ & $1.22 \pm 0.08$ & $1.15 \pm 0.09$ & $0.75 \pm 0.05^{\mathrm{a}}$ & $0.63 \pm 0.06^{\mathrm{a}}$ \\
\hline & $(9.90)$ & $(45.54)$ & $(50.00)$ & $(66.81)$ & $(69.71)$ \\
\hline \multirow[t]{2}{*}{ RAUT 1000} & $0.68 \pm 0.16$ & $1.56 \pm 0.07$ & $1.19 \pm 0.10$ & $0.74 \pm 0.04^{\mathrm{a}}$ & $0.60 \pm 0.08^{\mathrm{a}}$ \\
\hline & $(32.67)$ & $(30.36)$ & $(48.26)$ & $(67.26)$ & $(71.15)$ \\
\hline \multirow[t]{2}{*}{ ASP 150} & $0.47 \pm 0.08^{\mathrm{a}}$ & $0.63 \pm 0.09^{a}$ & $0.48 \pm 0.10^{\mathrm{a}}$ & $0.31 \pm 0.05^{\mathrm{a}}$ & $0.23 \pm 0.04^{\mathrm{a}}$ \\
\hline & $(53.47)$ & $(71.87)$ & $(76.81)$ & $(86.28)$ & $(88.94)$ \\
\hline
\end{tabular}

Values presented as Mean \pm SEM; superscript ${ }^{a}$ represents statistically significant difference at $p<0.05$ versus control; Repeated Measures ANOVA followed by Bonferonni's post-hoc test; RAUT = Residual Aqueous Fraction of Uapaca togoensis, ASP = Aspirin; $\mathrm{n}=6$; Values in parentheses are percentage inhibition of inflammation

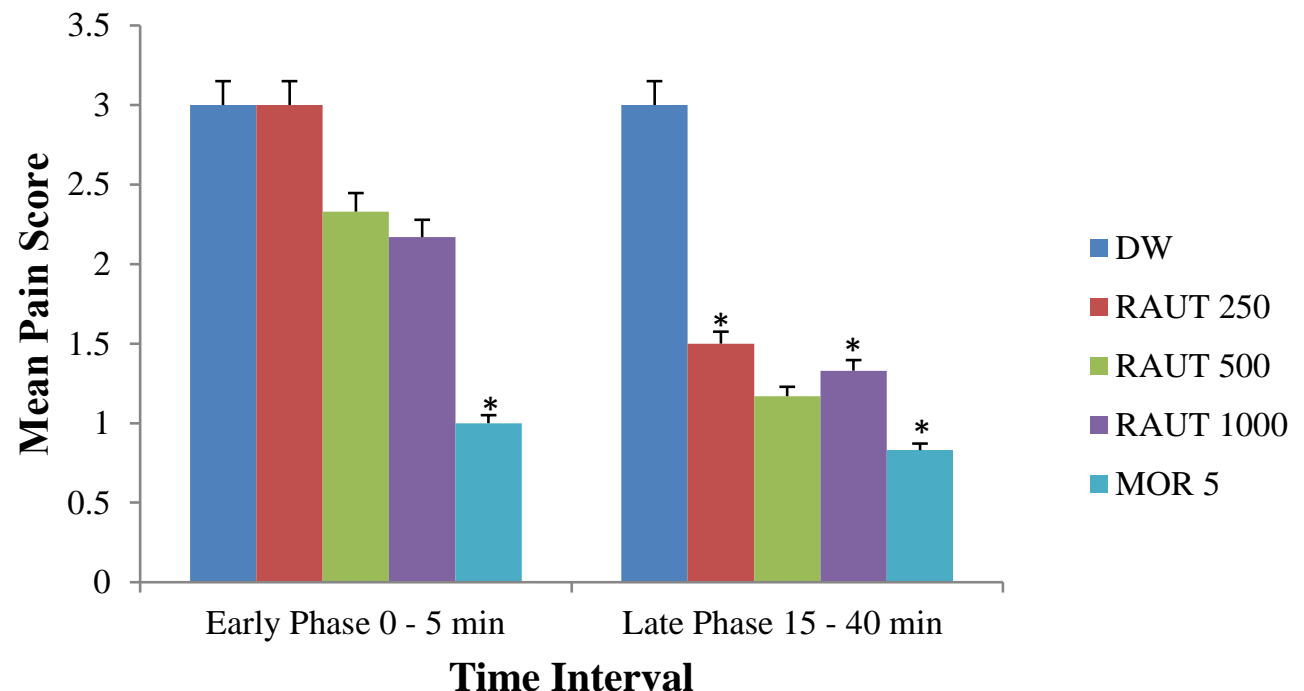

Figure 1: Effect of Residual Aqueous Fraction of Uapaca togoensis on Formalin-induced Pain Test in Mice Values are presented as Mean score $\pm \mathrm{SEM} ;{ }^{\mathrm{a}}=\mathrm{p}<0.05$ significant decrease in pain score compared with control; Data were analyzed with Kruskal-Wallis followed by Tukey's post hoc Test; DW = Distilled Water (10 ml/kg); RAUT = Residual Aqueous Fraction of Uapaca togoensis; MOR = Morphine; n=6 


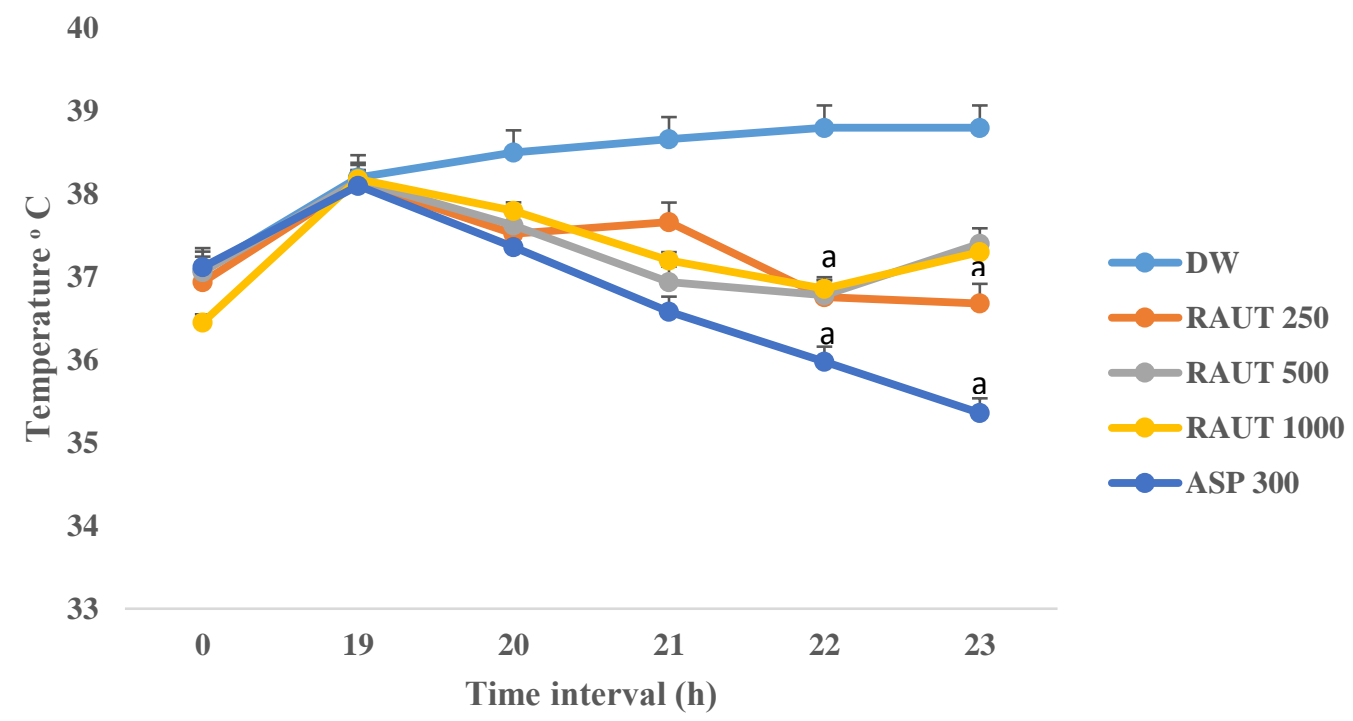

Figure 2: Effect of Residual Aqueous Fraction of Uapaca togoensis on Brewers's Yeast induced Pyrexia in Rats Data was analyzed using repeated measures ANOVA followed by Bonferroni Post Hoc test, ${ }^{a}=p<0.05$ significant decrease in temperature as compared to the peak of temperature. RAUT = Residual Aqueous Fraction of Uapaca togoensis, ASP = Aspirin, $\mathrm{h}=$ hour

\section{DISCUSSION}

The present study was aimed to evaluate the analgesic, anti-inflammatory and anti-pyretic potential of the residual aqueous fraction of Uapaca togoensis in animal models of pain, inflammation and fever. The stem bark and leaves of the plant has been previously reported to be used traditionally for the treatment of different ailments including pain [12]. Moreover, in vivo analgesic and antiinflammatory activity of the crude methanol extract has been previously reported [19]. This study attempted to further evaluate the analgesic, anti-inflammatory and antipyretic activities of the residual aqueous fraction of the plant.

The oral $\mathrm{LD}_{50}$ value of the fraction in both rats and mice were greater than 5000 $\mathrm{mg} / \mathrm{kg}$ body weight. There were no signs/symptoms of toxicity (such as reduced motor activity, restlessness, convulsions, coma, diarrhea and lacrimation) observed. This suggests that the fraction is practically nontoxic orally, at acute dose levels according to the lethal dose classification of toxic levels of chemicals by Lorke [22].
The acetic acid-induced abdominal writhing test is an effective screening method used to evaluate compounds for peripherally and centrally acting analgesic activities [28]. The intraperitoneal injection of acetic acid causes the release and accumulation of endogenous substances (including PGE2, PGF2 $\alpha$, PGI2, serotonin, histamine, lipoxygenase products and peritoneal mast cells) which directly activate nociceptors to cause pain [29]. Mice respond to this chemical (acetic acid) stimulus by contracting the abdominal muscles followed by extension of hind limbs and elongation of body parts, and such constriction is thought to be mediated by the local peritoneal receptors [30]. Aspirin and other NSIADs reduce acetic acid-induced writhes by blocking the synthesis and or release of these endogenous pain and inflammatory mediators [31]. RAUT reduced the number of acetic acid-induced writhes suggesting peripherally mediated analgesic activity mediated by blocking the synthesis and or release of endogenous substances responsible for painful sensations. 
The formalin-induced pain test has been reliably used to measure the ability of a substance to relieve moderate continuous pain generated by an injured tissue. The test is a highly predictive pain model which mimics acute and clinical pain. Behavioral indicators which were graded into scores were used to assess the analgesic effect of the fraction in this study [32]. Generally, the formalin-induced pain test is a three-phase process - the early stage (the first $90 \mathrm{~min}$ ) during which histamine and serotonin are released; the second stage (90-150 min) which is mediated by kinin; and the third stage (after $180 \mathrm{~min}$ ), which is controlled by prostaglandin release [33]. In the present study, the oral administration of the residual aqueous fraction significantly reduced the mean pain score notably in the second phase of the formalin test. This thus suggests that the fraction likely to act by hindering the release and/or action of prostaglandin.

The hot plate model was used to assess RAUT for central analgesic activity. The fraction significantly prolonged the reaction latency to pain thermal-induced pain in mice. However, morphine the standard drug suppressed the thermal pain response of animals better than the fraction. Compounds that can prolong reaction time to thermal stimulus are considered to possess centrally acting analgesic activity [34]. Thus, the ability of RAUT to prolong pain latency time suggests activity via central pain pathways probably by modulating endogenous substances (including substance $\mathrm{P}$, endogenous opioids, somatostatin and other inhibitory hormones) which are the targets of pain and inflammation in addition to opioid receptors [35]. According to, Hassan et al., [36] central mediation of pain has been found to involve many complex processes including opiate, serotonergic, dopaminergic and descending noradrenergic systems. The fraction may thus be acting through any of these systems to produce its centrally mediated analgesic activity.
The anti-inflammatory activity of the fraction was evaluated using the carrageenan-induced paw edema model in rats [26]. The subcutaneous injection of carrageenan (a phlogistic agent) into a rat paw causes a severe inflammatory reaction resulting from the biphasic release of various inflammatory mediators [37]. The early phase of edema (1-2 $\mathrm{h}$ ), which is not inhibited by NSAIDs such as indomethacin or aspirin is mainly due to the release of histamine, 5-hydroxytryptamine (5HT) and bradykinin. The late phase (3 to $5 \mathrm{~h}$ ) which can be blocked by NSAIDs has been linked with elevated productions of PGs, protease and lysosome, and more recently has been attributed to the induction of inducible COX-2 in the hind paw [38]. In the present investigation, administration of the extract produced significant inhibition of the late phase edema induced by the sub-plantar injection of carrageenan with no inhibitory effect in the first phase of test. In contrast the standard drug (morphine) significantly inhibited both phases. The obtained results suggest that the fraction may be acting similarly to NSAIDs by reducing inflammation, swelling and pain through the inhibition of prostaglandin synthesis mediated by bradykinins, leukotrienes and polymorphonuclear cells [39].

Brewer's yeast induced pyrexia which is considered as pathogenic fever suggests the role of prostaglandins in the thermoregulation of body temperature [1]. Exogenous pyrogens like Brewer's yeast led to the production of different pro-inflammatory cytokines which stimulate the release of prostaglandins by entering into the hypothalamic circulation thus changing the hypothalamic thermal set point [40]. Thus, the ability of a substance/drug/extract to inhibit prostaglandins synthesis can be considered as a useful test for its anti-pyretic potential. The present study revealed that RAUT produced a dose dependent reduction in body temperature. This suggests that the extract may be exerting 
antipyretic action through inhibition of prostaglandin synthetase within the hypothalamus similar to the NSAIDs.

Qualitative phytochemical screening revealed the presence of flavonoids, saponins, tannins, alkaloids, glycosides, triterpenes and steroids in the RAUT. These secondary metabolites have been reported to have different extents of analgesic and antiinflammatory activities [41-44]. Therefore, the observed analgesic and anti-inflammatory effects may be due to the presence of one or a combination of these bioactive constituents acting singly or in combination.

Conclusion. Results from this study suggests that the residual aqueous fraction of methanol stem bark extract of Uapaca togoensis possesses analgesic, anti-inflammatory and anti-pyretic activities. The fraction could therefore offer potential benefit in the management of pain, inflammation and fever.

\section{Acknowledgements}

The authors are grateful to the Department of Pharmacology and Therapeutics, Ahmadu Bello University, Zaria, Nigeria, for approving the use of its Animal House Facility and Laboratory equipment.

\section{REFERENCES}

1. Walter EJ, Hanna-Jumma S, Carraretto M, Forni L. The pathophysiological basis and consequences of fever. Crit Care. 2016; 20:200.

2. International Society for the Study of Pain (IASP, 2018). Pain Definitions.

3. Tamrat, Y, Nedi T, Assefa S, Teklehaymanot, T, Shbeshi W. Anti-inflammatory and analgesic activities of solvent fractions of the leaves of Moringa stenopetala Bak. (Moringaceae) in mice models; BMC. Complement. Altern. Med. 2017; 17, 473. doi: 10.1186/s12906-017-1982-y.

4. Yomgjun Z, Tingjie Z, Xiaoqui Y, Zhiying F, Feng Q, Guangke X, Jinfeng L, Fachuan N, Xiahong J. Yanqing. L. A survey of chronic pain in China. Libyan J. of Med. 2020; 15 (1). doi: $10.1080 / 19932820.2020 .1730550$
5. Abdulkhaleq LA, Assi MA, Abdullah R, Zamri-Saad M, Taufiq-Yap YH, Hezmee MNM. The crucial roles of inflammatory mediators in inflammation: A review. Vet World. 2018;11(5):627-635. doi:10.14202/vetworld.2018.627-635

6. Snafi AE. Arabian Medicinal Plants with Analgesic and Antipyretic Effects Plant Based Review (Part 1). IOSR J. Pharm. 2018; Volume 8, Issue 6 Version. II (June 2018), PP. 81-102

7. Blomqvist A, Engblom D. Neural mechanisms of inflammation-induced fever. The Nueroscientist. 2018; 24 (4): 381-399

8. Aryal S, Adhikari B, Panthi K, Aryal P, Mallik SK, Bhusal RP, Salehi B, Setzer WN, Sharifi-Rad J, Koirala N. Antipyretic, Antinociceptive, and AntiInflammatory Activities from Pogostemon benghalensis Leaf Extract in Experimental Wistar Rats. Medicines, 2019; 6(4), 96; https://doi.org/10.3390/medicines6040096

9. Labianca R, Sarzi-Puttini P, Zuccaro SM, Cherubino P, Vellucci R, Fornasari D. Adverse effects associated with non-opioid and opioid treatment in patients with chronic pain. Clin. Drug. Investig. 2012, 32, 53-63.

10. Kifayatullah M, Rahim H, Jan NU, Kamran A C, Ullah I, Abbas S. In vivo Analgesic, Antipyretic and Anti-inflammatory Activities of ethanol extract of Pericampylus glaucus in experimental animals. Sains Malaysiana 48(3)(2019): 629-635

11. World Health Organization (2003). Traditional Medicine. Factsheet No. 134. www.who.int/medicines/publications/traditional/trm strategy14_23/en/

12. Koné WM, Atindehou KK, Kacou-N'Douba A, Dosso M. Evaluation of 17 medicinal plants from Northern Côte D'Ivoire for their in vitro activity against Streptococcus pneumoniae. Afr. J. Tradit. Complement. Altern. Med. 2007. 4, 17-22.

13. Burkill HM. The Useful Plants of West Tropical Africa. Volume 3, Royal Botanic Gardens, Kew, UK. 1985. pp. 233.

14. Azokou A, Koné MW, Koudo BG, Tra Bi HF. Larvicidal Potential of some Plants from West Africa against Culex quinquefasciatus (Say) and Anopheles gambiae Giles (Diptera: Culicidae). J Vector Borne Dis. 2013. 2: 103-110.

15. Omachi AA, Ndukwe GI, Sallau MS, Ayo RG. Phytochemical screening and antimicrobial studies of Uapaca togoensis (pax) stem bark extracts. Int. J. Eng. Sci. 2015. 4, 24-28. 
16. Seukep, J. A., Sandjo, L. P., Ngadjui, B. T. and Kuete, V. Antibacterial Activities of the Methanol Extracts and Compounds from Uapaca togoensis against gram-negative multi-drug resistant phenotypes. S. Afr. J. Bot. 2016. 103(1):1-5 doi: 10.1016/j.sajb.2015.08.014

17. Olorukooba AB, Maiha BB, Chindo BA, Ejiofor JI, Hamza AN. Antiplasmodial studies on the ethyl acetate fraction of the stem bark extract of Uapaca togoensis (Pax.) Euphorbiaceae in Mice. BAJOPAS. 2016. 9(1): 191-196

18. Kuete V, Sandjo LP, Seukep JA, Zeino M, Mbaveng AT, Ngadjui B, Efferth T. Cytotoxic compounds from the fruits of Uapaca togoensis towards multifactorial drug-resistant cancer cells. Planta Med. 2015. 81(1), 32-8. doi: 10.1055/s-00341383362

19. Olorukooba AB, Maiha BB, Chindo BA, Ejiofor JI, Hamza AN, Khan F. Preliminary studies on the analgesic and anti-inflammatory activities of the methanol stem bark extract of Uapaca togoensis Pax. (Euphorbiaceae) in Rodents. Niger. J. Pharm. Sci. 2015. 14, 24-32.

20. Ciulei, L. (1997); Methodologies for the analysis of vegetable drugs. UNIDO, Romani, pp 68 -70 .

21. Trease GE, Evans WC. Phytochemistry, In: Textbook of Pharmacognosy 4th Edition, WB Sanders Company Ltd. London, UK. 20012. pp. 224343.

22. Lorke D. A new approach to acute toxicity testing. Arch. Toxicol. 1983. 54, 275-287.

23. Koster R, Anderson M, De Beer EJ. Acetic acid for analgesic screening; Fed. Proc. 1959. 18, 412-7.

24. Tjolsen A, Berge OG, Hunskaar S, Rosland JH, Hole K. The formalin test. An evaluation of the method. Pain. 1992. 79, 105-111.

25. Eddy NB, Leimbach D. Synthetic analgesics. ii. dithienylbutenyl- and dithienylbutylamines; J. Pharmacol. Exp. Ther. 1953. 107, 385-93.

26. Winter EA, Risley EA, Nuss G. Antiinflammatory and antipyretic activities of indomethacin, 1-(p-chlorobenzoyl)-5-methoxy-2methylindole-3-acetic acid. J. Pharm. Exp. Ther. 1963. 141, 369-376.

27. Somezeet P, Choudhury NSK, Jagannath PV, Dipti KP, Goutam KJ. Analgesic, antipyretic and antiinflammatory effect of the whole plant extract of Desmostachya bipinnata Stapf (Poaceae) in albino rats. Drug Invent. Today. 2009. 1(2), 150-153.
28. Kakoti BB, Pradhan P, Borah S, Mahato K, Kumar M. Analgesic and antiinflammatory activities of the methanolic stem bark extract of Nyetanthes arbortrsitis Linn. BioMed Res. Int. 2013. http://dx.doi.org/10.1155/2013/826295.

29. Matsuda M, Huh Y, Ji RR. Roles of inflammation, neurogenic inflammation, and neuroinflammation in pain. J. Anesth. 2018 doi: $10.1007 / \mathrm{s} 00540-018-2579-4$. in press. [

30. Bentley GA, Newton SH, Starr J. Studies on the antinociceptive action of $\alpha$-agonist drugs and their interactions with opioid mechanisms; Br. J. Pharmacol. 1983. 79, 125-134.

31. Donkor K, Stephen A, Jerry A, Nutifafa T, Nii, OM, Laud KO. Analgesic and anti-inflammatory activities of Asena, a herbal preparation for treatment of arthritis, using rodent models; Med. Aromat. Plant. Res. J. 2013. 1, 20-29.

32. Dubuisson D, Dennis SR. The formalin test: a quantitative study of the analgesic effects of morphine, meperidine and brain stem stimulation in rats and cats. Pain. 1997. 4, 161-174.

33. Rock EM, Limebeer CL, Parker LA. Effect of cannabidiolic acid and $\Delta 9$-tetrahydrocannabinol on carrageenan-induced hyperalgesia and edema in a rodent model of inflammatory pain. Psychopharmacology. 2018. 235:3259-3271. doi: 10.1007/s00213-018-5034-1.

34. Fan SH, Ali NA, Basri DF. Evaluation of analgesic activity of the methanol extract from the galls of Quercus infectoria (Olivier) in rats. Evid. Based Complement. Alternat. Med. 2014. 2014:976764. doi: 10.1155/2014/976764.

35. Khan, H., Saeed, M., Khan, M.A., Dar, A. and Khan, I., 2010. The antinociceptive activity of Polygonatum verticillatum rhizomes in pain models. Journal of Ethnopharmacology, 127 (2), 521-527

36. Hassan SMR, Hossain MM, Aktar R, Mazumder MEH, Alam MA, Faruque A, Rana S, Rahman S. Analgesic activity of aerial parts of Commelina benghalensis Linn. Int. J. Pharm. 2010. 6(1), 63-67.

37. Prajapati VD, Maheriya PM, Jani GK, Solanki HK. Carrageenan: a natural seaweed polysaccharide and its applications; Carbohydr. Polym. 2014. 105, 97-112.

38. Eddouks M, Chattopadhyay D, Zeggwagh NA. Animal models as tools to investigate antidiabetic and anti-inflammatory plants; Evid. Based. Complement. Alternat. Med. 2012. 1-14. 
39. Kaushik D, Kumar A, Kaushik P, Rana AC, Analgesic and anti-inflammatory activity of Pinus roxburghii Sarg. Adv. pharmacol. sci. 2012. 1-6.

40. Bhowmick R, Sarwar MS, Rahman SM. In vivo analgesic, antipyretic, and anti-inflammatory potential in Swiss albino mice and in vitro thrombolytic activity of hydroalcoholic extract from Litsea glutinosa leaves. Biol Res. 2014. 47, 56 https://doi.org/10.1186/0717-6287-47-56.

41. Funakoshi-Tago M, Nakamura K, Tago K, Mashino T, Kasahara T. Anti-inflammatory activity of structurally related flavonoids, apigenin, luteolin and fisetin. Int. Immunopharmacol. 2011. 11, 1150-9.

42. Foyet HS, Abdou Bouba A, Ponka R, Asongalem AE, Kamtchouing P, Nastasa V. Effects of Hibiscus asper leaves extracts on carrageenan induced oedema and complete Freund's adjuvantinduced arthritis in rats. J. Cell Anim. Biol. 2011. 5, 69-75

43. Hernández-Ortega M, Ortiz-Moreno A, Hernández-Navarro M, Chamorro-Cevallos $\mathrm{G}$, Dorantes-Alvarez L, Necoechea-Mondragón H. Antioxidant, antinociceptive and anti-inflammatory effects of carotenoids extracted from dried pepper (Capsicum annuum L); J. Biomed. Biotechnol. 2012. $1-10$.

44. Bellik Y, Laïd B, Hasan AA, Balkees AB, Fatiha A, Hammoudi SM, Mokrane I. Molecular mechanism underlying anti-inflammatory and antiallergic activities of phytochemicals: An update. Molecules. 2013. 18, 322- 353. 